\title{
Tungstate as a synergist to phosphonate-based formulation for corrosion control of carbon steel in nearly neutral aqueous environment
}

\author{
B V APPA RAO ${ }^{\mathrm{a}, *}$, M VENKATESWARA RAO $^{\mathrm{a}}$, S SRINIVASA RAO $^{\mathrm{a}}$ and B SREEDHAR ${ }^{\mathrm{b}}$ \\ ${ }^{a}$ Department of Chemistry, National Institute of Technology Warangal (NITW), Warangal 506004 \\ ${ }^{b}$ Inorganic and Physical Chemistry Division, Indian Institute of Chemical Technology, \\ Hyderabad 500007 \\ e-mail: boyapativapparao@rediffmail.com, chemysri@yahoo.com
}

MS received 25 October 2009; revised 31 March 2010; accepted 6 April 2010

\begin{abstract}
Synergistic inhibition of corrosion of carbon steel in low chloride aqueous medium using tungstate as a synergist in combination with $N, N$-bis(phosphonomethyl) glycine (BPMG) and zinc ions is presented. The synergistic action of tungstate has been established through the present studies. The new ternary inhibitor formulation is effective in neutral and slightly acidic as well as slightly alkaline media. Potentiodynamic polarisation studies inferred that the formulation functions as a mixed inhibitor. Impedance studies of the metal/solution interface revealed that the surface film is highly protective. Characterisation by X-ray photoelectron spectroscopy (XPS) of the surface film formed in presence of the inhibitor revealed the presence of iron, phosphorus, nitrogen, oxygen, carbon, zinc and tungsten in the surface film. The chemical shifts in the binding energies of these elements inferred that the surface film is composed of iron oxides/hydroxides, zinc hydroxide, heteropolynuclear complex [Fe(III), Zn(II)-BPMG] and $\mathrm{WO}_{3}$. Reflection absorption FTIR spectroscopic studies also supported the presence of these compounds in the surface film. Morphological features of the metal surface studied in the absence and presence of the inhibitor by scanning electron microscopy (SEM) are also presented. Based on all these results, a plausible mechanism of corrosion inhibition is proposed.
\end{abstract}

Keywords. Carbon steel; tungstate; corrosion inhibitor; synergistic effect; protective film; phosphonated glycine.

\section{Introduction}

Phosphonate-based formulations are well known as corrosion inhibitors for carbon steel in aqueous environments. Synergistic effect existing between phosphonic acids and zinc ions on corrosion control of carbon steel has been studied by several researchers. ${ }^{1-9} N, N$-bis (phosphonomethyl) glycine (BPMG) is one among the phosphonic acids reported as corrosion inhibitors in combination with zinc ions. ${ }^{6}$ It was reported to be an environmentally friendly phosphonic acid $^{6}$ and it can form complexes with metal ions like $\mathrm{Fe}^{2+}, \mathrm{Fe}^{3+}$ and $\mathrm{Zn}^{2+} \cdot{ }^{10,11}$ In order to develop the inhibitor formulation containing relatively low concentration of BPMG, addition of one more synergist to the binary system, BPMG- $\mathrm{Zn}^{2+}$,

\footnotetext{
*For correspondence
}

has been thought of in the present study. For this purpose, an inorganic compound namely sodium tungstate was chosen as the second synergist for the following reasons. Sodium tungstate possesses very low toxicity. ${ }^{12} \mathrm{~A}$ few reports are available in literature stating that tungstate acts as a corrosion inhibitor for steel either alone ${ }^{13}$ or synergistically in combination with other compounds. ${ }^{14}$ The objectives of the present study are to investigate the synergistic action of tungstate in combination with BPMG- $\mathrm{Zn}^{2+}$ for corrosion control of carbon steel in nearly neutral aqueous solution and to study the inhibitive properties of the surface film formed by the ternary inhibitor system, BPMG- $\mathrm{Zn}^{2+}$-tungstate. For all these studies, $200 \mathrm{ppm}$ of sodium chloride solution has been chosen as control because of the following reason. The water used in cooling water systems is generally either demineralised water or unpolluted surface water. In either case, the aggressiveness of 
the water does not normally exceed that of $200 \mathrm{ppm}$ of $\mathrm{NaCl}$ solution.

\section{Experimental}

\subsection{Materials}

For all the studies, the specimens taken from a single sheet of carbon steel of the following composition were chosen: $\mathrm{C}: 0 \cdot 1-0.2 \%, \mathrm{P}: 0.03-0.08 \%, \mathrm{~S}$ : $0.02-0.03 \%, \mathrm{Mn}: 0.4-0.5 \%$ and the rest was iron. Prior to the tests, the specimens were polished to mirror finish with $1 / 0,2 / 0,3 / 0$ and $4 / 0$ grade emery polishing papers respectively, washed with distilled water, degreased with acetone and dried. For gravimetric measurements, the polished specimens of the dimensions, $3.5 \mathrm{~cm} \times 1.5 \mathrm{~cm} \times 0.2 \mathrm{~cm}$, were used while for electrochemical and surface analytical studies, the dimensions of the specimens were $1.0 \mathrm{~cm} \times 1.0 \mathrm{~cm} \times 0.1 \mathrm{~cm}$. Electrochemical studies were carried out at an immersion period of $1 \mathrm{~h}$ and for the surface analytical studies, the immersion period was 7 days. $N, N$-bis (phosphonomethyl) glycine (BPMG) obtained from Aldrich Chemical Company Inc., USA, was used as such. The molecular structure of BPMG is shown in figure 1. Sodium tungstate $\left(\mathrm{Na}_{2} \mathrm{WO}_{4}\right)$, zinc sulphate $\left(\mathrm{ZnSO}_{4} \cdot 7 \mathrm{H}_{2} \mathrm{O}\right)$, sodium chloride and other reagents were analytical grade chemicals. All the solutions were prepared using triple distilled non-deaerated water. $\mathrm{pH}$ values of the solutions were adjusted using $0.01 \mathrm{~N} \mathrm{NaOH}$ and $0.01 \mathrm{~N} \mathrm{H}_{2} \mathrm{SO}_{4}$ solutions. An aqueous solution consisting of $200 \mathrm{ppm}$ of sodium chloride has been used as the control throughout the studies.

\subsection{Gravimetric measurements}

For all the gravimetric experiments, the polished specimens were weighed and immersed in duplicate, in $100 \mathrm{~mL}$ control solution in the absence and pres-ence of inhibitor formulations of different

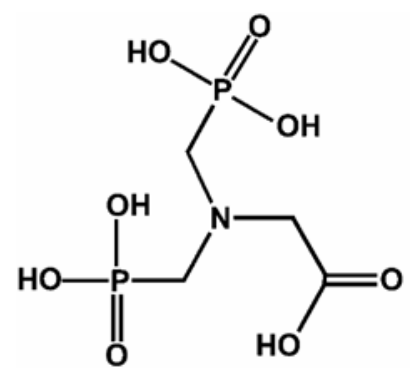

Figure 1. Molecular structure of BPMG. concentrations, for a period of seven days. Then the specimens were reweighed after washing, degreasing and drying. Accuracy in weighing up to $0.01 \mathrm{mg}$ and in surface area measured up to $0.1 \mathrm{~cm}^{2}$, as recommended by ASTM G31, was followed. ${ }^{15}$ Inhibition efficiencies $\left(I E_{\mathrm{g}}\right)$ of the inhibitor formulations were calculated using the formula:

$$
I E_{\mathrm{g}}(\%)=100\left[(C R)_{\mathrm{O}}-(C R)_{\mathrm{I}}\right] /(C R)_{\mathrm{O}}
$$

where $(C R)_{\bigcirc}$ and $(C R)_{\mathrm{I}}$ are the corrosion rates in the absence and presence of inhibitor respectively.

Gravimeric studies were carried out on the ternary system containing BPMG (20-30 ppm), $\mathrm{Zn}^{2+}$ (20$30 \mathrm{ppm})$ and tungstate $(0-200 \mathrm{ppm})$ to establish minimum concentrations of both BPMG and $\mathrm{Zn}^{2+}$ in presence of tungstate for effective inhibition. The effect of $\mathrm{pH}$ on inhibition efficiency was determined in case of the effective ternary inhibitor formulations.

\subsection{Electrochemical studies}

Electrochemical impedance spectroscopic (EIS) studies and potentiodynamic polarisation studies were carried out using Electrochemical Workstation Model IM6e Zahner-electrik, GmbH, Germany and the experimental data were analysed by using the Thales software. The measurements were conducted in a conventional three-electrode cylindrical glass cell with platinum electrode as auxiliary electrode and saturated calomel electrode (SCE) as reference electrode. The working electrode was carbon steel embedded in epoxy resin of polytetrafluoroethylene so that the flat surface of $1 \mathrm{~cm}^{2}$ was the only surface exposed to the electrolyte. The three-electrode set up was immersed in control solution of volume $500 \mathrm{~mL}$ both in the absence and presence of various inhibitor formulations and allowed to attain a stable open circuit potential (OCP).

Polarisation curves were recorded in the potential range of -650 to $-150 \mathrm{mV}$ with a resolution of $2 \mathrm{mV}$. The curves were recorded in the dynamic scan mode with a scan rate of $2 \mathrm{mV} / \mathrm{s}$. The ohmic drop compensation has been made during the studies. The corrosion potential $\left(E_{\text {corr }}\right)$, corrosion current density $\left(i_{\text {corr }}\right)$ and anodic Tafel slope $\left(\beta_{a}\right)$ and cathodic Tafel slope $\left(\beta_{c}\right)$ were obtained by Tafel extrapolation method. The inhibition efficiencies $\left(I E_{p}\right)$ were calculated from $i_{\text {corr }}$ values using the equation $^{16}$ 


$$
I E_{p}(\%)=100\left[1-\left(i_{\text {corr }}^{\prime} / i_{\text {corr }}\right)\right],
$$

where $i_{\text {corr }}$ and $i^{\prime}{ }_{\text {corr }}$ are the corrosion current densities in case of the control and inhibitor solutions respectively.

Impedance spectra in the form of Nyquist plots were recorded at OCP in the frequency range from $60 \mathrm{kHz}$ to $10 \mathrm{mHz}$ with 4 to 10 steps per decade. The charge transfer resistance $\left(R_{c t}\right)$, constant phase element (CPE) and CPE exponent $(n)$ were obtained from Nyquist plots. The inhibition efficiencies $\left(I E_{i}\right)$ were calculated using the equation,

$$
I E_{i}(\%)=100\left[1-\left(R_{c t} / R_{c t}^{\prime}\right)\right]
$$

where $R_{c t}$ and $R_{c t}^{\prime}$ are the charge transfer resistance values in the absence and presence of the inhibitor respectively.

\subsection{Surface analysis by $X$-ray photoelectron spectroscopy (XPS)}

XPS measurements of the surface films were carried out with Kratos analytical photoelectron spectrometer model AXIS 165 with monochromated Al $\mathrm{K}_{\alpha}$ $\mathrm{X}$-ray source $(1486.6 \mathrm{eV})$ operated at $100 \mathrm{~W}$ and with a resolution of $0 \cdot 1 \mathrm{eV}$. Analyser pass energy was $80 \mathrm{eV}$, with a step of $0 \cdot 1 \mathrm{eV}$ for the elements of interest namely $\mathrm{Fe} 2 p, \mathrm{P} 2 p, \mathrm{~N} 1 s, \mathrm{C} 1 s, \mathrm{O} 1 s, \mathrm{Zn} 2 p$ and $\mathrm{W} 4 f$.

\subsection{Fourier transform infrared (FTIR) spectroscopic studies}

FTIR spectra were recorded using FTIR spectrophotometer from Thermo Electron Corporation, USA, model Nexus 670 with a resolving power of $0.125 \mathrm{~cm}^{-1}$. The detector is temperature stabilised DTGS ( $\mathrm{KBr}$ window) and liquid nitrogen cooled MCT-A and the beam splitter is XT-KBr. FTIR spectra of pure BPMG and pure sodium tungstate were recorded using $\mathrm{KBr}$ pellet method. The reflection absorption FTIR spectra of the surface films were recorded in the wave number range of 4000 $400 \mathrm{~cm}^{-1}$. The measurements were made at a grazing angle of $85^{\circ}$.

\subsection{Surface analysis by scanning electron microscopy (SEM)}

SEM images were recorded using FEI Quanta FEG 200 high resolution scanning electron microscope for the specimens immersed in the control as well as in the inhibitor solution at two different magnifications.

\section{Results and discussion}

\subsection{Gravimetric studies}

The results of gravimetric studies using the binary system, BPMG- $\mathrm{Zn}^{2+}$, at various concentrations of both the constituents indicated that the minimum concentrations of BPMG and $\mathrm{Zn}^{2+}$ in the binary system are $40 \mathrm{ppm}$ and $30 \mathrm{ppm}$ respectively for inhibition efficiency $(I E)>90 \%$. Before the addition of tungstate to the binary system, BPMG $-\mathrm{Zn}^{2+}$, the inhibitive effect of sodium tungstate alone was studied. The results of these studies indicated that sodium tungstate alone is not an effective inhibitor at low concentration levels. It was also reported in literature that sodium tungstate can be an effective inhibitor at the concentration of $300 \mathrm{ppm}$ and it becomes more effective when the concentration exceeds $1200 \mathrm{ppm} .{ }^{17}$ When the possible binary combination of BPMG and tungstate is considered for gravimetric studies, it was inferred that this combination is not effective in corrosion control even at higher concentrations of both the components. As tungstate is being added to the binary formulation, $\mathrm{BPMG}-\mathrm{Zn}^{2+}$, it is expected that the required minimum concentrations of BPMG and $\mathrm{Zn}^{2+}$ in the ternary inhibitor formulation are still lower than $40 \mathrm{ppm}$ and $30 \mathrm{ppm}$ respectively for an effective inhibition. Hence, the concentrations of both BPMG and $\mathrm{Zn}^{2+}$ are reduced by $10 \mathrm{ppm}$ each and the formulations consisting of BPMG $(30 \mathrm{ppm})+\mathrm{Zn}^{2+}(20 \mathrm{ppm})+$ tungstate $(20-200 \mathrm{ppm})$, are considered for the study of their IE. Figure 2 shows that none of these formulations showed an IE $>90 \%$. When the concentration of $\mathrm{Zn}^{2+}$, which plays very important role in phosphonate-based inhibitor formulations, is increased from 20 to $30 \mathrm{ppm}$, it has made the ternary inhibitor system effective in corrosion inhibition. Interestingly, the reduction in the concentration of BPMG from 30 to $20 \mathrm{ppm}$ in the ternary formulation showed a very little effect on IE. Thus, in order to achieve an IE > $90 \%$, the required minimum concentrations of BPMG and $\mathrm{Zn}^{2+}$ are $20 \mathrm{ppm}$ and $30 \mathrm{ppm}$ respectively in presence of tungstate. While the binary system consisting of $20 \mathrm{ppm}$ BPMG and $30 \mathrm{ppm} \mathrm{Zn}^{2+}$ accelerates corrosion, with the addition of tungstate, 
the $I E$ of the ternary formulation increased gradually with increase in concentration of tungstate reaching $99 \%$ at $200 \mathrm{ppm}$. It may be mentioned here that the molar ratio of $\mathrm{BPMG} / \mathrm{Zn}^{2+} /$ tungstate is $1 \cdot 0: 5.4: 9.5$ to exhibit excellent synergism. The role of each synergist is explained under mechanistic aspects of corrosion inhibition later in this paper.

The influence of $\mathrm{pH}$ on $I E$ values of various compositions of the ternary system, BPMG- $\mathrm{Zn}^{2+}$ tungstate, in the $\mathrm{pH}$ range from 5.0 to 9.0 is shown in figure 3. No adverse effect on the $I E$ is observed with a decrease of $\mathrm{pH}$ from neutral to slightly acidic i.e. from $\mathrm{pH} 7.0$ to $6 \cdot 0$. But on further decrease in $\mathrm{pH}$ from $6 \cdot 0$ to $5 \cdot 0$, the $I E$ values are drastically decreased in case of all the ternary formulations. In the alkaline region, at the $\mathrm{pH} 8 \cdot 0$, the ternary formulations containing $200 \mathrm{ppm}$ of tungstate are found to be effective. On further increase of $\mathrm{pH}$ to 9.0 , the ternary inhibitor system is proved to be ineffective. From these results, it may be concluded that the ternary system, BPMG- $\mathrm{Zn}^{2+}$-tungstate, is effective in the neutral and slightly acidic as well as slightly alkaline media.

\subsection{Potentiodynamic polarisation studies}

The potentiodynamic polarisation curves of carbon steel electrode in $200 \mathrm{ppm} \mathrm{NaCl}$ solution at $\mathrm{pH} 7$ in the absence and presence of various inhibitor combinations are shown in figure 4 . The Tafel parameters derived from these curves and the inhibition

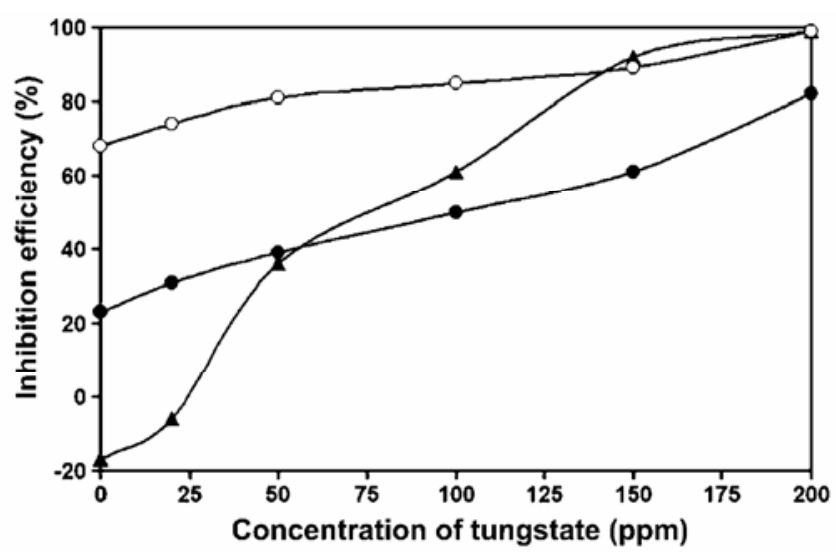

Figure 2. Corrosion inhibition efficiency of the ternary inhibitor formulations containing BPMG, $\mathrm{Zn}^{2+}$ and tungstate as a function of concentration of tungstate: - BPMG $(20 \mathrm{ppm})+\mathrm{Zn}^{2+}(30 \mathrm{ppm})+$ tungstate; BPMG $(30 \mathrm{ppm})+\mathrm{Zn}^{2+}(20 \mathrm{ppm})+$ tungstate; $\rightarrow$ BPMG (30 ppm) $+\mathrm{Zn}^{2+}(30 \mathrm{ppm})+$ tungstate. efficiency values $\left(I E_{p}\right)$ are listed in table 1 . The corrosion potential $\left(E_{\text {corr }}\right)$ in case of the control is $-323.4 \mathrm{mV}$ vs SCE and the corresponding corrosion current density $\left(i_{\text {corr }}\right)$ is $12.84 \mu \mathrm{A} / \mathrm{cm}^{2}$. From figure 4 , it is clear that in case of all the inhibitor combinations studied, both the anodic and cathodic current density values are decreased when compared to the control. It is, thus, evident that all these formulations work as mixed type inhibitors. When the combination of $20 \mathrm{ppm}$ BPMG and $30 \mathrm{ppm} \mathrm{Zn}^{2+}$ is con-

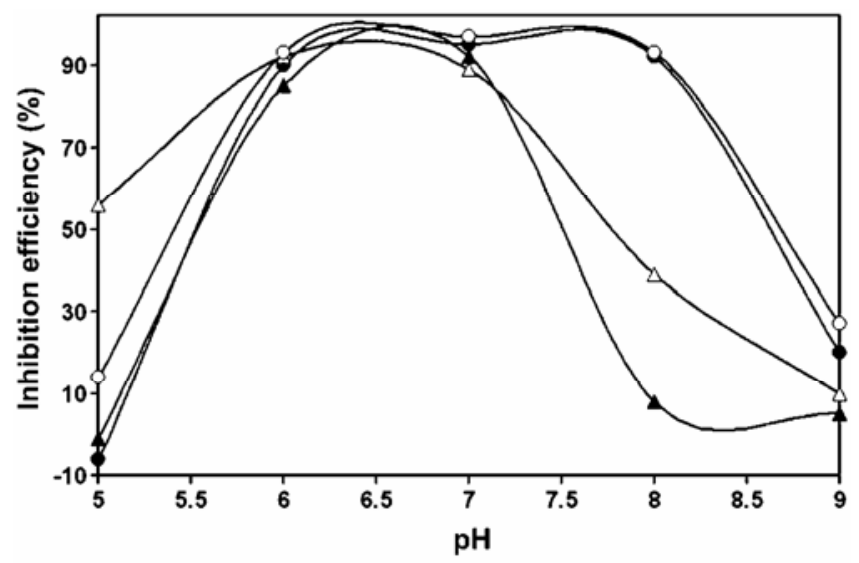

Figure 3. Corrosion inhibition efficiencies of the ternary inhibitor formulations as a function of $\mathrm{pH}$ BPMG $(20 \mathrm{ppm})+\mathrm{Zn}^{2+}$ (30 ppm) + tungstate $(150 \mathrm{ppm})$; $\rightarrow-B P M G \quad(20 \mathrm{ppm})+\mathrm{Zn}^{2+} \quad(30 \mathrm{ppm})+$ tungstate (200 ppm); $\triangle$ BPMG $(30 \mathrm{ppm})+\mathrm{Zn}^{2+}(30 \mathrm{ppm})+$ tungstate $(150 \mathrm{ppm}) ; \multimap$ BPMG $(30 \mathrm{ppm})+\mathrm{Zn}^{2+}$ $(30 \mathrm{ppm})+$ tungstate $(200 \mathrm{ppm})$.

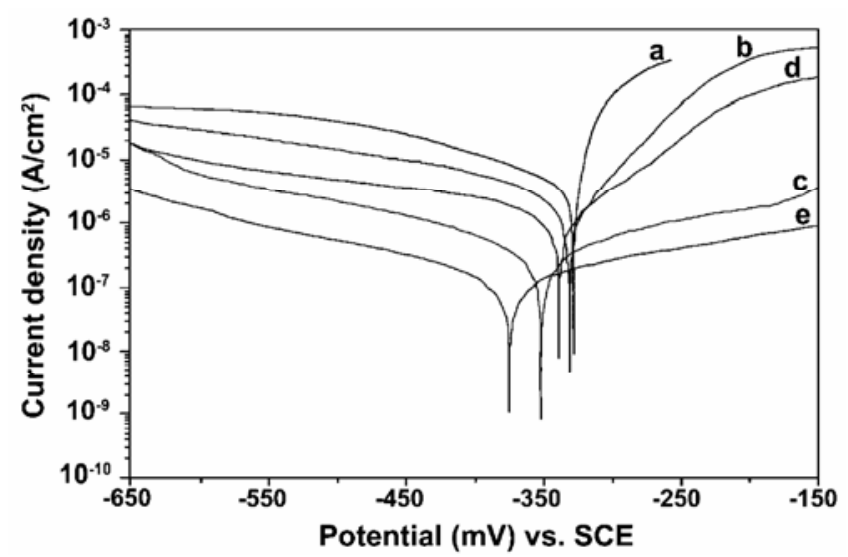

Figure 4. Potentiodynamic polarisation curves for carbon steel in various aqueous environments, (a) $\mathrm{NaCl}$ (200 ppm); (b) $\mathrm{NaCl}$ (200 ppm) + BPMG (20 ppm) + $\mathrm{Zn}^{2+}$ (30 ppm); (c) $\mathrm{NaCl}(200 \mathrm{ppm})+\operatorname{BPMG}(20 \mathrm{ppm})+$ $\mathrm{Zn}^{2+}$ (30 ppm) + tungstate (200 ppm); (d) $\mathrm{NaCl}(200 \mathrm{ppm})+$ BPMG (30 ppm) $+\mathrm{Zn}^{2+}$ (30 ppm); (e) $\mathrm{NaCl}(200 \mathrm{ppm})+$ BPMG (30 ppm) $+\mathrm{Zn}^{2+}(30 \mathrm{ppm})+$ tungstate $(200 \mathrm{ppm})$. 
Table 1. Tafel parameters for carbon steel in $200 \mathrm{ppm} \mathrm{NaCl}$ environment in the absence and presence of inhibitor formulations.

\begin{tabular}{|c|c|c|c|c|c|c|c|}
\hline \multicolumn{3}{|c|}{ Concentration (ppm) } & \multicolumn{4}{|c|}{ Tafel parameters } & \multirow[b]{2}{*}{$I E_{\mathrm{p}}(\mathbf{\%})$} \\
\hline BPMG & $\mathrm{Zn}^{2+}$ & Tungstate & $E_{\text {corr }}(\mathrm{mV}$ vs $\mathrm{SCE})$ & $i_{\text {corr }}\left(\mu \mathrm{A} / \mathrm{cm}^{2}\right)$ & $\beta_{a}(\mathrm{mV} /$ decade $)$ & $\beta_{\mathrm{c}}(\mathrm{mV} /$ decade $)$ & \\
\hline 0 & 0 & 0 & $-323 \cdot 4$ & $12 \cdot 84$ & 45 & 132 & - \\
\hline 20 & 30 & 0 & $-330 \cdot 8$ & $7 \cdot 11$ & 54 & 112 & $44 \cdot 62$ \\
\hline 20 & 30 & 200 & $-354 \cdot 9$ & $1 \cdot 12$ & 51 & 74 & $91 \cdot 28$ \\
\hline 30 & 30 & 0 & $-341 \cdot 5$ & 5.93 & 57 & 98 & 53.81 \\
\hline 30 & 30 & 200 & $-373 \cdot 0$ & 0.85 & 63 & 71 & $93 \cdot 38$ \\
\hline
\end{tabular}

sidered, there is a slight shift of corrosion potential to cathodic side and the shift in cathodic Tafel slope is greater than the shift in anodic Tafel slope. The corrosion current density is decreased from 12.84 to $7.11 \mu \mathrm{A} / \mathrm{cm}^{2}$, corresponding to an inhibition efficiency of only $44.62 \%$. But, by the addition of $200 \mathrm{ppm}$ of tungstate to the above formulation, $E_{\text {corr }}$ is shifted to the extent of $31.5 \mathrm{mV}$ towards cathodic side. The corrosion current density is decreased significantly to $1.12 \mu \mathrm{A} / \mathrm{cm}^{2}$, corresponding to an inhibition efficiency of $91.28 \%$. In case of the ternary formulation also, the shift in cathodic Tafel slope is higher than that in anodic Tafel slope. Similar results are obtained in case of the other ternary inhibitor formulation, BPMG $(30 \mathrm{ppm})+\mathrm{Zn}^{2+}$ $(30 \mathrm{ppm})+$ tungstate $(200 \mathrm{ppm})$, considered for the study by polarisation method. All these results indicate that the ternary inhibitor formulation retards both the anodic dissolution of carbon steel and oxygen reduction at cathodic sites in the corrosion inhibition process. Nevertheless, the effect on cathodic reaction is more pronounced. Similar phosphonatebased formulations were reported to be mixed inhibitors. ${ }^{2,8,9}$ Thus, the results of potentiodynamic polarisation studies infer the synergistic effect of tungstate as well as the synergistic effect of the ternary inhibitor formulation in corrosion control of carbon steel.

\subsection{Electrochemical impedance studies}

Nyquist plots for carbon steel immersed in $200 \mathrm{ppm}$ of $\mathrm{NaCl}$ solution at $\mathrm{pH} 7$ in the absence and presence of various formulations are shown in figure 5 . In case of the control as well as in presence of various formulations, the Nyquist plots are found to be depressed semicircles instead of ideal semicircles and all the Nyquist plots are characterised by single time constant. The experimental data obtained from these plots are fitted by the equivalent electrical circuit shown in figure 6 . Such an equivalent circuit was also discussed by several researchers, who obtained similar depressed semicircles with single time constant. ${ }^{18-20}$ The charge transfer resistance $\left(R_{c t}\right)$, constant phase element (CPE) and CPE exponent $(n)$ obtained from the Nyquist plots and the calculated inhibition efficiency values $\left(I E_{i}\right)$ are shown in table 2 .

In the present study, in the presence of the control alone, a small semicircle with an $R_{c t}$ value of $2575 \Omega$ is observed. When the combination of $20 \mathrm{ppm}$ of BPMG and $30 \mathrm{ppm}$ of $\mathrm{Zn}^{2+}$ is considered in presence of the control, slight increase in $R_{\mathrm{ct}}$ is observed with a decrease in CPE value to the extent of only $4.5 \mu \mathrm{F} / \mathrm{cm}^{2}$. But, on the addition of $200 \mathrm{ppm}$ of tungstate to this binary formulation, a large depressed semicircle is observed from high frequency to low frequency regions in the Nyquist plot, indicating that the charge transfer resistance becomes dominant in the corrosion processes due to the presence of protective film on the metal surface. This result is supported by the significant decrease in $\mathrm{CPE}$ and an increase in $\mathrm{n}$ value. The value of $R_{\mathrm{ct}}$ in case of the ternary formulation is $44059 \Omega$, which is about ten times the $R_{c t}$ value obtained in case of the binary combination of BPMG/ $/ \mathrm{Zn}^{2+}$. The CPE value is found to decrease from $13.41 \mu \mathrm{F} / \mathrm{cm}^{2}$ in case of the control to $2.83 \mu \mathrm{F} / \mathrm{cm}^{2}$ in case of the ternary inhibitor formulation. This is because of the replacement of water molecules in the electrical double layer by the organic molecules having low dielectric constant. ${ }^{21}$ The value of $\mathrm{n}$ is considerably increased to 0.913 in presence of the ternary inhibitor system, suggesting the increase of homogeneity of the interface during inhibition. Similar results are obtained when the concentration of BPMG is increased from 20 to $30 \mathrm{ppm}$. All these results indicate that there is formation of a protective film in the presence of the 
Table 2. Impedance parameters for carbon steel in $200 \mathrm{ppm} \mathrm{NaCl}$ environment in the absence and presence of inhibitor formulations.

\begin{tabular}{|c|c|c|c|c|c|c|}
\hline \multicolumn{3}{|c|}{ Concentration (ppm) } & \multicolumn{3}{|c|}{ Impedance parameters } & \multirow[b]{2}{*}{$I E_{i}(\mathbf{\%})$} \\
\hline BPMG & $\mathrm{Zn}^{2+}$ & Tungstate & $R_{\mathrm{ct}}\left(\Omega \mathrm{cm}^{2}\right)$ & $\mathrm{CPE}\left(\mu \mathrm{F} / \mathrm{cm}^{2}\right)$ & $n$ & \\
\hline 0 & 0 & 0 & 2,575 & 13.41 & 0.592 & - \\
\hline 20 & 30 & 0 & 4,420 & 8.91 & 0.697 & 41.74 \\
\hline 20 & 30 & 200 & 44,059 & $2 \cdot 83$ & 0.913 & $94 \cdot 15$ \\
\hline 30 & 30 & 0 & 5,965 & 6.54 & 0.684 & 56.83 \\
\hline 30 & 30 & 200 & 63,287 & $2 \cdot 11$ & 0.905 & 95.93 \\
\hline
\end{tabular}

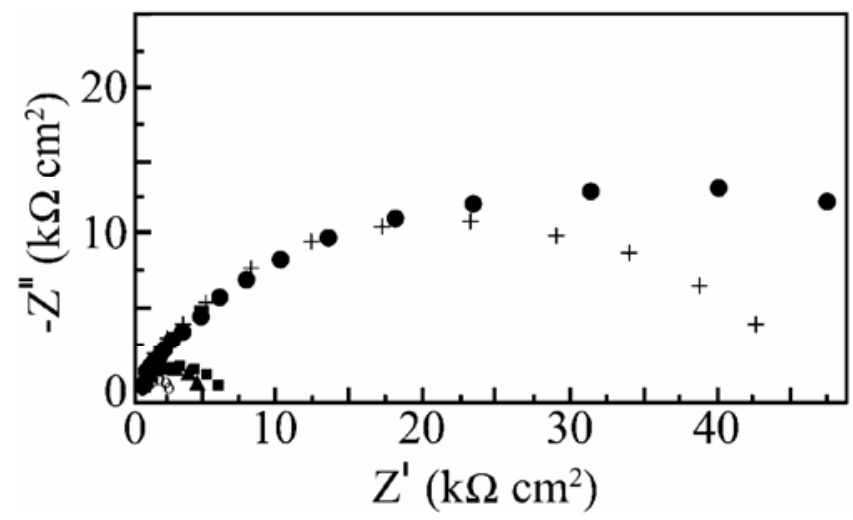

Figure 5. Nyquist plots for carbon steel in various aqueous environments, (O) $\mathrm{NaCl}(200 \mathrm{ppm}) ;(\boldsymbol{\Delta}) \mathrm{NaCl}$ $(200 \mathrm{ppm})+\mathrm{BPMG}(20 \mathrm{ppm})+\mathrm{Zn}^{2+}(30 \mathrm{ppm}) ;(+) \mathrm{NaCl}$ $(200 \mathrm{ppm})+\mathrm{BPMG}(20 \mathrm{ppm})+\mathrm{Zn}^{2+}(30 \mathrm{ppm})+$ tungstate (200 ppm); (ם) $\mathrm{NaCl}(200 \mathrm{ppm})+\mathrm{BPMG}(30 \mathrm{ppm})+$ $\mathrm{Zn}^{2+}(30 \mathrm{ppm}) ;(\bullet) \mathrm{NaCl}(200 \mathrm{ppm})+\operatorname{BPMG}(30 \mathrm{ppm})+$ $\mathrm{Zn}^{2+}(30 \mathrm{ppm})+$ tungstate $(200 \mathrm{ppm})$.

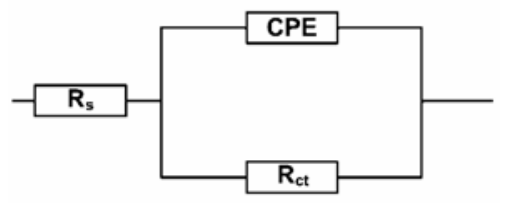

Figure 6. The equivalent circuit used to fit the impedance spectra.

ternary inhibitor formulation. Several authors, who studied the inhibitory effects of phosphonate-based corrosion inhibitors, also reported that there is formation of a thick and less permeable protective film on the metal surface. ${ }^{2,48}$ They also concluded that the protective film consists of phosphonate-metal complexes. The impedance results of the present study also infer the synergistic action operating between BPMG, $\mathrm{Zn}^{2+}$ and tungstate. This inference is in agreement with the inferences drawn from gravimetric studies and potentiodynamic polarisation studies. It may be noted that the inhibition efficiency values obtained from impedance studies are in agreement with those values obtained from polarisation studies. However, the inhibition efficiency values obtained from gravimetric studies are found to be slightly different from those obtained from electrochemical studies. This is due to different immersion periods used in these studies.

\section{$3.4 X$-ray photoelectron spectroscopic studies}

The XPS survey spectrum of the surface film formed in the presence of the inhibitor formulation, BPMG $(20 \mathrm{ppm})+\mathrm{Zn}^{2+}(30 \mathrm{ppm})+$ tungstate $(200 \mathrm{ppm})$, is shown in figure 7 . The survey spectrum of the surface film formed in the absence of any inhibitor and the deconvolution spectra of various elements present in the surface films formed in the absence as well as in the presence of the inhibitor formulation, are not shown here. However, the XPS deconvolution spectra of the elements namely $\mathrm{P}, \mathrm{N}, \mathrm{Zn}$ and $\mathrm{W}$ are given in the supporting information. The interpretation of all these spectra is done with the help of the data of the elemental binding energies reported in literature and also with the help of the reports published on the analysis of XPS spectra of the surface films.

The spectrum corresponding to the inhibitor system shows the $\mathrm{Fe} 2 p_{3 / 2}$ peak at $712.0 \mathrm{eV}$. It indicates that $\mathrm{Fe}^{3+}$ is involved in the complex formation with BPMG apart from being present in the form of oxides/hydroxides like $\mathrm{Fe}_{2} \mathrm{O}_{3}, \mathrm{Fe}_{3} \mathrm{O}_{4}, \mathrm{FeOOH}$, etc. ${ }^{22-24}$ However, these oxides/hydroxides of iron are present in very small quantities in the surface film formed by the inhibitor formulation as evident from the significant decrease in the intensity of $\mathrm{Fe} 2 p_{3 / 2}$ peak in presence of the inhibitor. No peak is observed due to elemental iron in the case of control as well as inhibitor formulation. This result infers 
the formation of thick films in both the cases. The film is non-protective in the case of control and highly protective in the presence of inhibitor molecules. The binding energy of $\mathrm{Fe}^{2+}$ state in iron oxides is reported to be around $708.5 \mathrm{eV}^{25}$ The absence of any peak in this region in the present study also supports that iron does not exist in $\mathrm{Fe}^{2+}$ state. The XPS spectrum of phosphorus showed two P $2 p$ peaks one each at 133.4 and $134.2 \mathrm{eV}$. The peaks are shifted from their characteristic elemental binding energies of $130.0 \mathrm{eV}$ for $\mathrm{P} 2 p_{3 / 2}$ and $131.0 \mathrm{eV}$ for $\mathrm{P} 2 p_{1 / 2}{ }^{26}$ Based on the literature reports, ${ }^{4,7,27,28}$ the $\mathrm{P} 2 p$ peaks observed in the present study suggest the presence of BPMG in the surface film in the form of complex with the metal ions. The XPS spectrum of the surface film in presence of the inhibitor shows the $\mathrm{N} 1$ s peak at $400 \cdot 2 \mathrm{eV}$, which is shifted from the characteristic elemental binding energy of $398.0 \mathrm{eV} .{ }^{26}$ The shift may be attributed to the presence of BPMG molecules in the surface film in the form of a complex with the metal ions. It was reported in literature ${ }^{29}$ that $\mathrm{N} 1 s$ peak observed at $399.7 \mathrm{eV}$ could be assigned to the presence of $(=\mathrm{N}-)$ in the molecule adsorbed on the metal surface. Meneguzzi et al reported that the peak at $399.9 \mathrm{eV}$ could be attributed to the neutral imine $(-\mathrm{N}=)$ and amine $(-\mathrm{N}-\mathrm{H})$ nitrogen atoms. ${ }^{30}$

The deconvolution spectrum of $\mathrm{C} 1 s$ has three peaks one each at $284.6 \mathrm{eV}, 285.5 \mathrm{eV}$ and $288.4 \mathrm{eV}$. The presence of multiple peaks in the $\mathrm{C} 1 s$ spectrum in case of the inhibitor can be attributed to various carbon environments present in BPMG. This inference is supported by several literature reports. ${ }^{7,19,31}$ In the XPS deconvolution spectrum of $\mathrm{O} 1 s$, a single peak of high intensity was observed at $531.5 \mathrm{eV}$. In the light of the results and interpretations reported in literature, ${ }^{4,8,25,32}$ the $\mathrm{O} 1 s$ peak of high intensity

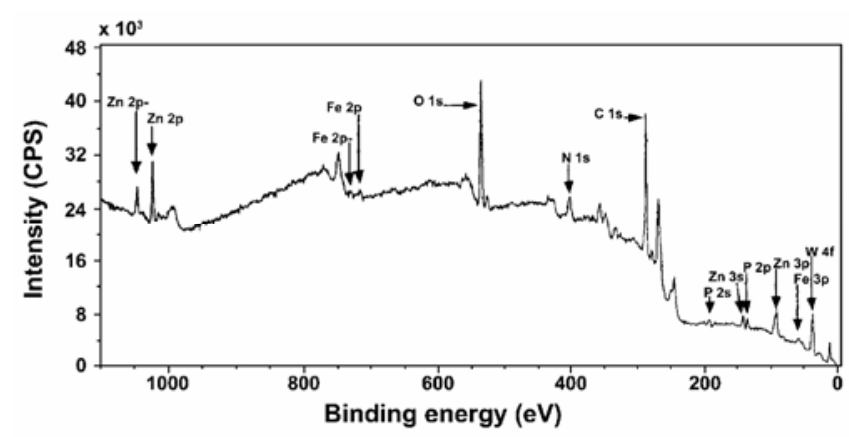

Figure 7. XPS spectrum of the surface film formed in presence of the inhibitor formulation, BPMG $(20 \mathrm{ppm})+$ $\mathrm{Zn}^{2+}(30 \mathrm{ppm})+$ tungstate $(200 \mathrm{ppm})$. observed in the present study may be interpreted as follows. The XPS of surface film shows that besides oxygen, there is presence of carbon, nitrogen, phosphorus, iron, zinc and tungsten in the surface film. That means BPMG is present on the surface, zinc is present as $\mathrm{Zn}^{2+}$ and the interpretation given above in case of $\mathrm{Fe} 2 p$ indicates the presence of $\mathrm{Fe}_{2} \mathrm{O}_{3}, \mathrm{Fe}_{3} \mathrm{O}_{4}$ and $\mathrm{FeOOH}$. Hence, $\mathrm{O} 1 s$ peaks can be ascribed to the presence of $\mathrm{Zn}(\mathrm{OH})_{2}, \mathrm{Fe}_{2} \mathrm{O}_{3}, \mathrm{Fe}_{3} \mathrm{O}_{4}, \mathrm{FeOOH}$ and oxygen of BPMG as well as tungsten oxide in the surface film.

The XPS deconvolution spectrum of zinc showed the $\mathrm{Zn} 2 p_{3 / 2}$ peak at $1023.0 \mathrm{eV}$ and the $\mathrm{Zn} 2 p_{1 / 2}$ peak at $1046.0 \mathrm{eV}$. $\mathrm{Zn} 2 p_{3 / 2}$ peak is normally interpreted. The high intensity of the $\mathrm{Zn} 2 p_{3 / 2}$ peak may be ascribed to the presence of $\mathrm{Zn}(\mathrm{OH})_{2}$ in the surface film and also to the involvement of $\mathrm{Zn}^{2+}$ in the complex formation with BPMG. It was reported in literature that the $\mathrm{Zn} 2 p_{3 / 2}$ peak at $1022.8 \mathrm{eV}$ was due to the presence of $\mathrm{Zn}(\mathrm{OH})_{2}$ in the surface film. ${ }^{33}$ Felhosi et al interpreted from the XPS analysis that there is formation of [Zn-HEDP] complex on the mild steel surface when immersed in a solution consisting of a mixture of HEDP and $\mathrm{Zn}^{2+} .4$ In the XPS deconvolution spectrum of tungsten, the two peaks observed one each at 35.9 and $38.0 \mathrm{eV}$ indicate the presence of tungsten in the surface film. The former peak corresponds to $\mathrm{W} 4 f_{7 / 2}$ electron, which is shifted from characteristic elemental binding energy of $31.0 \mathrm{eV}$ and the latter peak corresponds to $\mathrm{W} 4 f_{5 / 2}$ electron, which is shifted from $33.6 \mathrm{eV} .{ }^{34}$ The extent of shift is found to be very high in case of both the peaks. Such large shifts indicate that tungsten exists in the oxidation state of VI (in the form of $\mathrm{WO}_{3}$ ) in the surface film. This interpretation in case of tungsten is also supported by literature reports. ${ }^{12,35}$ After consolidating all the inferences drawn from the XPS of individual elements present in surface film, it is suggested that the surface film in case of the ternary inhibitor system consists of mainly [Zn(II)-BPMG] complex, $\mathrm{Zn}(\mathrm{OH})_{2}, \mathrm{WO}_{3}$ and small amounts of oxides/hydroxides of Fe(III). The complex may be chemisorbed on the metal surface and get attached to $\mathrm{Fe}(\mathrm{III})$ ions.

\subsection{Interpretation of FTIR spectra}

The reflection absorption FTIR spectra (not presented here) of the surface films formed on carbon steel in the absence and presence of the inhibitor are interpreted by comparing with the FTIR spectra of 
pure BPMG and pure sodium tungstate (not presented here) as well as with the help of literature reports. In the FTIR spectrum of BPMG, multiple bands in the region, $900-1200 \mathrm{~cm}^{-1}$ were assigned to phosphonate group stretching frequencies. The peak at $1181 \mathrm{~cm}^{-1}$ can be assigned to $-\mathrm{PO}_{3}$ antisymmetric $\left(v_{\mathrm{as}}\right)$ stretching while the peak at $1080 \mathrm{~cm}^{-1}$ is assigned to symmetric $\left(v_{\mathrm{s}}\right)$ stretching of $-\mathrm{PO}_{3}$. The peak observed at $933.5 \mathrm{~cm}^{-1}$ can be attributed to the $\mathrm{P}-\mathrm{OH}$ stretching vibrations. In case of the inhibited surface film, the antisymmetric and symmetric stretching vibrations, $v_{\text {as }}\left(\mathrm{PO}_{3}\right)$ and $v_{\mathrm{s}}\left(\mathrm{PO}_{3}\right)$ are observed in the form of a band at $1170 \mathrm{~cm}^{-1}$. This result can be interpreted in terms of interaction between $\mathrm{P}_{-} \mathrm{O}^{-}$present in the phosphonate with metallic species, viz. $\mathrm{Zn}(\mathrm{II})$ and $\mathrm{Fe}(\mathrm{III})$ to form $\mathrm{P}-\mathrm{O}-\mathrm{Zn}$ and $\mathrm{P}-\mathrm{O}-\mathrm{Fe}$ bonds. This interpretation was also given by several authors, who worked on corrosion inhibition of carbon steel by phosphonates. ${ }^{2,36,37}$ Carter et al found that FTIR spectra obtained with an organic phosphonate on a steel substrate are consistent with the phosphonate reaction on steel to produce a metal salt. ${ }^{38}$ This also suggests that phosphonates are coordinated with metal ions resulting in the formation of [metal-phosphonate] complexes on the metal surface. A weak band observed around $1320 \mathrm{~cm}^{-1}$ indicates the presence of zinc hydroxide in the surface film formed by the inhibitor. ${ }^{36,39,40}$

An intense band at $1732 \mathrm{~cm}^{-1}$ in the FTIR spectrum of BPMG is the characteristic of uncoordinated, protonated carboxylate carbonyl group in BPMG. The peak at $1700 \mathrm{~cm}^{-1}$ and at $1540 \mathrm{~cm}^{-1}$ in the reflection absorption FTIR spectrum of the surface film in case of the inhibitor system corresponds to the carbonyl group of BPMG in the surface film. The shifts in the stretching frequency are resulted due to the involvement of BPMG in the complex formation. A band at $1010 \mathrm{~cm}^{-1}$ in case of the inhibitor is due to $\mathrm{C}-\mathrm{N}$ stretching vibration shifted from $1157 \mathrm{~cm}^{-1}$ observed in case of pure BPMG. The shift towards lower wave number indicates the formation of a coordinate bond between metal ions and phosphonate molecule. The peak observed at $925 \mathrm{~cm}^{-1}$ may be attributed to strong $\mathrm{W}-\mathrm{O}$ bond of oxide of tungsten. Koltypin et al observed a broad peak at a wave number less than $1000 \mathrm{~cm}^{-1}$ in the FTIR spectra of the prepared $\mathrm{WO}_{3}$ nanoparticles. ${ }^{41}$ There are several bands in the region, $1200-400 \mathrm{~cm}^{-1}$, in both the spectra of surface films. Many of these peaks imply the presence of various oxides and hydroxides of iron like $\mathrm{Fe}_{3} \mathrm{O}_{4}, \mathrm{FeOOH}$ and $\mathrm{Fe}_{2} \mathrm{O}_{3}{ }^{27,31,36,42} \mathrm{~A}$ moderately intense and a broad band formed at $3540.8 \mathrm{~cm}^{-1}$, in case of the control, can be assigned to the presence of $-\mathrm{OH}$ group on the surface. This hydroxyl group may be in the form of $\mathrm{FeOOH}$ and/or $\mathrm{Fe}(\mathrm{OH})_{3} .{ }^{43}$ Such peaks are observed in the spectra of the inhibited surface film also. These peaks can be assigned to the $-\mathrm{OH}$ group present in BPMG, to $\mathrm{Zn}(\mathrm{OH})_{2}$ and a small contribution of hydroxide of $\mathrm{Fe}(\mathrm{III})$ present in the inhibited film.

Thus, the reflection absorption FTIR spectrum of the surface film formed in presence of the inhibitor formulation infers the presence of [ $\mathrm{Zn}(\mathrm{II})-\mathrm{BPMG}$ ] complex, $\mathrm{Zn}(\mathrm{OH})_{2}, \mathrm{WO}_{3}$ and small amounts of oxides and hydroxides of $\mathrm{Fe}(\mathrm{III})$.

\subsection{Surface analysis by SEM}

Figure 8 shows the high resolution SEM images of the surfaces of carbon steel immersed for 7 days in the control in the absence and presence of the inhibitor, BPMG $(20 \mathrm{ppm})+\mathrm{Zn}^{2+}(30 \mathrm{ppm})+$ tungstate $(200 \mathrm{ppm})$. Figure $8 \mathrm{a}$ reveals that the surface is severely corroded and there is formation of different forms of corrosion products (iron oxides) on the surface in the absence of the inhibitor. The entire surface is covered by a scale-like black corrosion product, on which there is growth of another corrosion product appearing in the form of white clusters at several sites. A very few of such clusters are shown at sub-micron level in the Figure $8 \mathrm{~b}$. The morphological features of the inhibited surface are shown in figures $8 \mathrm{c}$ and $\mathrm{d}$. The corrosion product deposits observed in case of the control are not present on the inhibited surface. It indicates that the penetration of $\mathrm{Cl}^{-}$ions of the environment on to the substrate is controlled effectively through good surface coverage by the inhibitor film. The higher magnification (X5000) SEM image (figure 8d) of the inhibited surface contains some low depth inhomogeneities on the surface. But the closer look at such sites reveals that the inhomogeneities are due to the structural defects of the metal substrate and that these sites are also covered by the inhibitor film. Thus, the inhibitor film covers the entire metal surface. This observation also accounts for the high inhibition efficiency values obtained during the gravimetric studies of the inhibitor system. From the SEM analysis, it can be inferred that the surface film formed by the ternary inhibitor system exhibits good protective properties for carbon steel in low chloride media. 

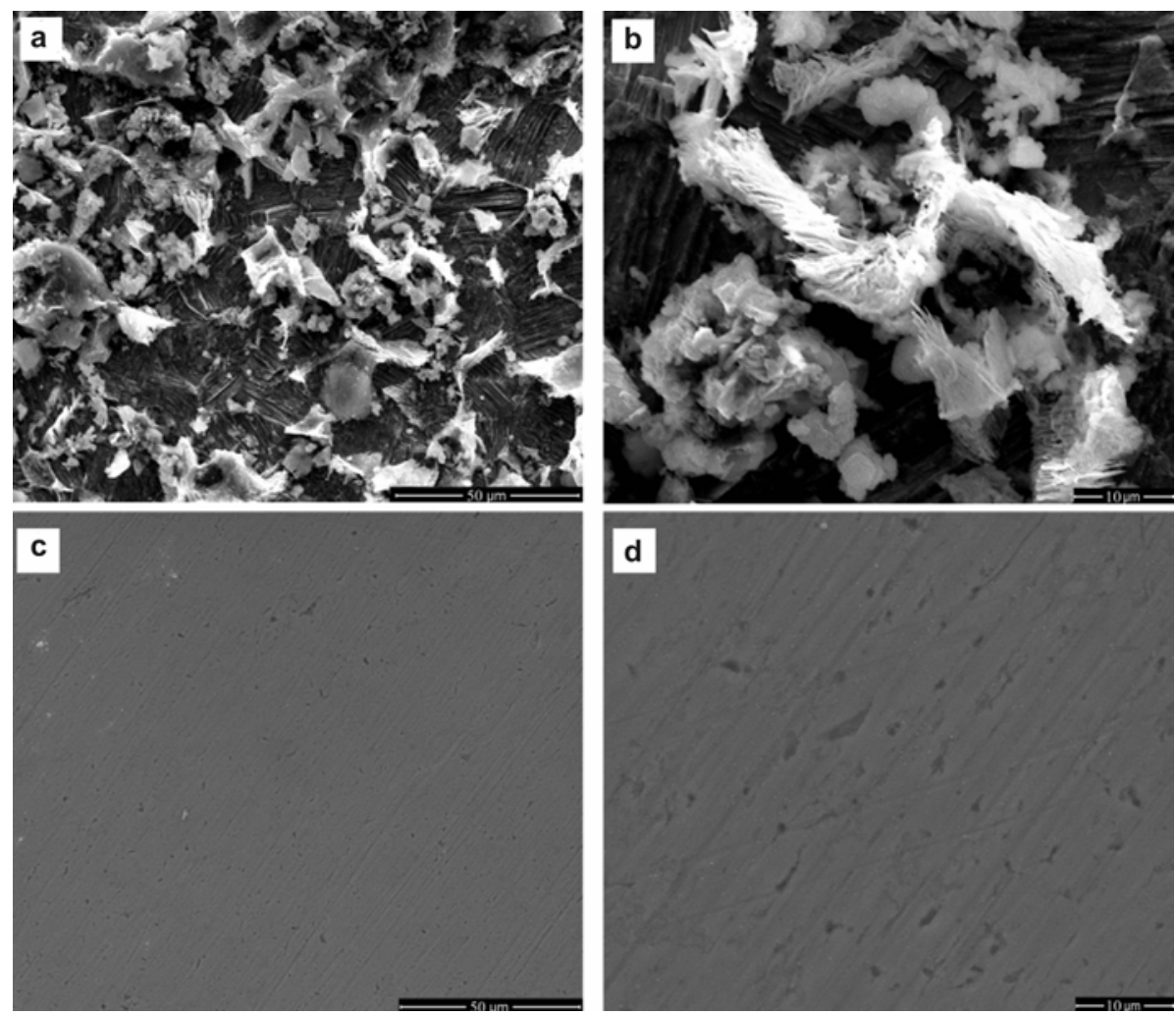

Figure 8. High-resolution SEM images of carbon steel surfaces after immersion in control in the absence and presence of the inhibitor, BPMG $(20 \mathrm{ppm})+\mathrm{Zn}^{2+}(30 \mathrm{ppm})+$ tungstate (200 ppm): (a) and (b) control, (c) and (d) inhibitor. (a) and (c) - magnification X1000, (b) and (b) - magnification X5000.

\subsection{Mechanism of corrosion inhibition}

In order to explain all the experimental results, a plausible mechanism of corrosion inhibition is proposed as follows:

(i) The mechanism of corrosion of carbon steel in nearly neutral aqueous media is well established. The well-known reactions are mentioned below.

$$
\mathrm{Fe} \rightarrow \mathrm{Fe}^{2+}+2 \mathrm{e}^{-},
$$

$\mathrm{Fe}^{2+}$ further undergoes oxidation in the presence of oxygen available in the aqueous solution.

$$
\mathrm{Fe}^{2+} \stackrel{\left[\mathrm{O}_{2}\right]}{\longrightarrow} \mathrm{Fe}^{3+}+\mathrm{e}^{-}
$$

The corresponding reduction reaction at cathodic sites in neutral and alkaline media is

$$
\mathrm{O}_{2}+2 \mathrm{H}_{2} \mathrm{O}+4 \mathrm{e}^{-} \rightarrow 4 \mathrm{OH}^{-}
$$

$\mathrm{Fe}^{3+}$ ions produced at anodic areas and $\mathrm{OH}^{-}$ions produced at cathodic areas combine to form
$\mathrm{Fe}(\mathrm{OH})_{3}, \quad\left(\mathrm{Fe}_{2} \mathrm{O}_{3} \cdot \mathrm{H}_{2} \mathrm{O}\right)$ which gets precipitated on the surface of the metal due to its very low solubility product.

(ii) When BPMG, $\mathrm{Zn}^{2+}$ and tungstate are added to the aqueous solution, BPMG reacts with $\mathrm{Zn}^{2+}$ to form a complex, $\left[\mathrm{Zn}^{2+}-\mathrm{BPMG}\right]$. It diffuses to the metal surface and binds to $\mathrm{Fe}$ (III) ions present on the surface. The cross-linkage and reorganisation of such complex ions on the surface will produce a polymeric network structure. The resulting polynuclear complex, [Fe(III), Zn(II)-BPMG] covers the anodic sites and controls the corresponding anodic reaction.

$$
\begin{aligned}
& {[\mathrm{Zn}(\mathrm{II})-\mathrm{BPMG}]+\mathrm{Fe}^{3+} \rightarrow } \\
& {[\mathrm{Fe}(\mathrm{III}), \mathrm{Zn}(\mathrm{II})-\mathrm{BPMG}] . }
\end{aligned}
$$

Tungstate ions produce tungsten oxide $\left(\mathrm{WO}_{3}\right)$, which along with the iron oxides contributes to the protective nature of the surface film. For example, it is possible that $\mathrm{WO}_{3}$ can react with $\mathrm{Fe}_{2} \mathrm{O}_{3}$ present on the surface to form iron tungstate. ${ }^{44}$ 


$$
\mathrm{WO}_{3}+\mathrm{Fe}_{2} \mathrm{O}_{3} \rightarrow \mathrm{Fe}_{2} \mathrm{WO}_{6}
$$

(iii) Free $\mathrm{Zn}^{2+}$ ions available in the bulk of the solution diffuse to the metal surface and react with $\mathrm{OH}^{-}$ions produced at the cathodic sites to form a precipitate of $\mathrm{Zn}(\mathrm{OH})_{2}$.

$$
\mathrm{Zn}^{2+}+2 \mathrm{OH}^{-} \rightarrow \mathrm{Zn}(\mathrm{OH})_{2} .
$$

The precipitate of $\mathrm{Zn}(\mathrm{OH})_{2}$ gets deposited on the cathodic sites and controls the cathodic partial reaction of corrosion process.

(iv) The inhibitor formulation is effective in the $\mathrm{pH}$ range, 6-8. At $\mathrm{pH} 9$ and above, higher concentration of $\mathrm{OH}^{-}$ions are available both in the bulk of the solution and on the surface. In such an environment, there is greater interference of $\mathrm{OH}^{-}$ions in the complexation $^{45}$ leading to the formation of [ $\mathrm{Zn}(\mathrm{II})$ BPMG-OH] complex, which may not contribute to the formation of protective film on the metal surface. In acidic medium at $\mathrm{pH} \leq 5$, the ligand will be in the protonated form and do not coordinate with $\mathrm{Zn}$ (II) as effectively as the deprotonated ligands. Secondly, enough amount of $\mathrm{Zn}(\mathrm{OH})_{2}$ will not be formed on the cathodic sites. Hence, the inhibitor is not effective at $\mathrm{pH} \leq 5$.

(v) Thus, BPMG, $\mathrm{Zn}^{2+}$ and tungstate play very important role in the synergistic effect in controlling corrosion through the formation of protective film on the metal surface. It is inferred that the film may consist of various oxides/hydroxides like $\mathrm{Fe}_{2} \mathrm{O}_{3}$, $\mathrm{Fe}_{3} \mathrm{O}_{4} \cdot \mathrm{H}_{2} \mathrm{O}, \mathrm{FeOOH}, \mathrm{Zn}(\mathrm{OH})_{2}, \mathrm{WO}_{3}$ and a polynuclear complex, [Fe(III), Zn(II)-BPMG]. Each of these constituents contributes itself to make the film highly protective.

\section{Conclusions}

(i) The new ternary inhibitor formulation, BPMG- $\mathrm{Zn}^{2+}$-tungstate, shows excellent synergistic effect in corrosion control of carbon steel in aqueous media.

(ii) Synergistic effect of tungstate is well established through the present studies.

(iii) The ternary formulation acts as a mixed type inhibitor controlling both the anodic and cathodic reactions.

(iv) The metal/solution interface is modified significantly in presence of the inhibitor, inferring the formation of a dense and protective film on the metal surface. (v) The inhibitor formulation is effective in the neutral and slightly acidic as well as slightly alkaline media.

(vi) Optimum amounts of each of the components of the inhibitor formulation are essential for an effective inhibition.

(vii) The protective film consists of mainly [ $\mathrm{Zn}$ (II)BPMG] complex, $\mathrm{Zn}(\mathrm{OH})_{2}, \mathrm{WO}_{3}$ and small amounts of oxides/hydroxides of Fe(III). Presence of optimum amounts of all these compounds is required to make the surface film protective.

\section{Supplementary information}

For supplementary information see www.ias.ac.in/ chemsci website.

\section{References}

1. Gunasekaran G, Palaniswamy N, Appa Rao B V and Muralidharan V S 1996 Proc. Indian Acad. Sci. (Chem. Sci.) 108399

2. Gonzalez Y, Lafont M C, Pebere N and Moran F 1996 J. Appl. Electrochem. 261259

3. Shaban A, Kalman E and Biczo I 1993 Corros. Sci. 351463

4. Felhosi I, Keresztes Zs, Karman F H, Mohai M, Bertoti I and Kalman E 1999 J. Electrochem. Soc. 146 961

5. Pech-Canul M A and Chi-Canul L P 1999 Corrosion 55948

6. Telegdi J, Shaglouf M M, Shaban A, Karman F H, Betroti I, Mohai M and Kalman E 2001 Electrochim. Acta 463791

7. Ochoa N, Baril G, Moran F and Pebere N 2002 J. Appl. Electrochem. 32497

8. Pech-Canul M A and Bartolo-Perez P 2004 Surf. Coat. Technol. 184133

9. Appa Rao B V, Srinivasa Rao S and Venkateswara Rao M 2008 Corros. Eng. Sci. Technol. 4346

10. Westerback S, Rajan K S and Martell A E 1965 J. Am. Chem. Soc. 872567

11. Sawada K, Duan W, Ono M and Satoh K 2000 J. Chem. Soc., Dalton Trans. 919

12. Lumsden J B and Szklarska-Smiralowska Z 1978 Corrosion 34167

13. Mu G, Li X, Qu Q and Zhou J 2006 Corros. Sci. 48 445

14. Qu Q, Li L, Bai W, Jiang S and Ding Z 2009 Corros. Sci. 512423

15. ASTM Standard G31-72 1999 (2004) Standard practice for laboratory immersion corrosion testing of metals, ASTM International, West Conshohocken, PA 2006 DOI: 10.1520/G0031-72R04.

16. Elachouri E, Hajji M S, Salem M, Kertit S, Aride J, Coudert R and Essassi E 1996 Corrosion 52103 
17. Aravio-Torre J and Arevalo A 1951 Inst. Espam. Oceanogr. $\mathbf{4 6} 27$

18. Morad M S 2000 Corros. Sci. 421307

19. Gunasekaran G and Chauhan L R 2004 Electrochim. Acta 494387

20. Alagta A, Felhosi I, Telegdi J, Bertoti I and Kalman E 2007 Corros. Sci. 492754

21. Wang C T, Chen S H, Ma H Y and Wang N X 2002 J. Serb. Chem. Soc. 67685

22. Kalman E, Karman F H, Cserny I, Kover L, Telegdi J and Varga D 1994 Electrochim. Acta 391179

23. McIntyre N S and Zetaruk D G 1977 Anal. Chem. 49 1521

24. Maroie S, Savy M and Verbist J J 1979 Inorg. Chem. 182560

25. Asami K, Hashimoto K and Shimodaira S 1976 Corros. Sci. 1635

26. Moulder J F, Stickle W F, Sobol P E and Bamben K D 1995 Handbook of X-ray photoelectron spectroscopy: a reference book of standard spectra for identification and interpretation of XPS data, USA, Physical Electronics

27. Nakayama N 2000 Corros. Sci. 421897

28. Koudelka M, Sanchez J and Augustynski J 1982 J. Electrochem. Soc. 1291186

29. El Azhar M, Traisnel M, Mernari B, Gengembre L, Bentiss F and Lagrenee M 2002 Appl. Surf. Sci. 185 197

30. Meneguzzi A, Ferreira C A, Pham M C, Delamar M and Lacaze P C 1999 Electrochim. Acta 442149
31. Aramaki K and Shimura T 2003 Corros. Sci. 45 2639

32. Fang J L, Li Y, Ye X R, Wang Z W and Liu Q 1993 Corrosion 49266

33. Aramaki K 2004 Corros. Sci. 461565

34. Sastri V S 1998 Corrosion inhibitors-principles and applications (England: John Wiley \& Sons)

35. Sastri V S and Packwood R H 1987 Werkstoffe and Korrosion $\mathbf{3 8} 77$

36. Amar H, Braisaz T, Villemin D and Moreau B 2008 Mater. Chem. Phys. 1101

37. To X H, Pebere N, Pelaprat N, Boutevin B and Hervaud Y 1997 Corros. Sci. 391925

38. Carter R O, Gierczak C A and Dickie R A $1986 \mathrm{Appl}$. Spectrosc. 40649

39. Sekine I and Hirakawa Y 1986 Corrosion 42272

40. Gunasekaran G, Palaniswamy N, Appa Rao B V and Muralidharan V S 1997 Electrochim. Acta 42 1427

41. Koltypin Yu, Nikitenko S I and Gedanken A 2002 J. Mater. Chem. 121107

42. Shi Yu and Gan Moog Chow 2004 J. Mater. Chem. 142781

43. Bellamy L J 1968 Advances in infrared group frequencies (Great Britain, The Chaucer Press Limited)

44. Pak J-J, Bahgat M and Paek M-K 2009 J. Alloy Compd. 477357

45. Deluchat V, Bollinger J-C, Serpaud B and Caullet C 1997 Talanta 44897 